\title{
A Rare Complication Following Trans-Conjunctival Lower Blepharoplasty
}

\section{Jorge Schwember ${ }^{1, *}$, Fernando Aguirre ${ }^{2}$, and Gerardo Schwember ${ }^{3}$}

${ }^{1}$ Centro Laser, La Serena, Chile

${ }^{2}$ Hospital San Juan de Dios, Servicio de Oftalmologia, La Serena, Chile

${ }^{3}$ Clinica Alemana de Santiago, Hospital Padre Hurtado de Santiago, Chile

*Corresponding author: Jorge Schwember, Centro Laser, Huanhuali 735, La Serena, 1720412, Chile, E-mail: jschwember@centrolaserlaserena.cl

Received: 26 Nov, 2019 | Accepted: 11 Dec, 2019 | Published: 18 Dec, 2019

Citation: Schwember J, Aguirre F, Schwember G (2019) A Rare Complication Following Trans-Conjunctival Lower Blepharoplasty. J Clin Cosmet Dermatol 3(3): dx.doi.org/10.16966/2576-2826.144

Copyright: (C) 2019 Schwember J, et al. This is an open-access article distributed under the terms of the Creative Commons Attribution License, which permits unrestricted use, distribution, and reproduction in any medium, provided the original author and source are credited.

\section{Letter to the Editor}

Transconjunctival blepharoplasty is the management of lower eyelid structures via the conjunctival approach and is applied, usually, to the cosmetic improvement of the lower eyelid using this approach $[1,2]$.

The transconjunctival approach was first described by Bourquet [3] in 1924 for the removal of lower eyelid fat. Tessier P [4] later advocated this approach, in 1973, for exposure of the orbital floor and the maxilla for the treatment of facial traumas and maxillofacial anomalies. Nowadays is a common access to eliminate the eyelid fat pads. The addition of laser resurfacing improves the aesthetic result.

\section{Results}

A Blepharoplasty with an inferior trans-conjunctival lid approach and Er:YAG laser resurfacing were performed on a 63-year old female patient (Figure 1). She presented a symmetrical dermatochalasis. The surgical procedure was carried out under local anesthesia plus mild sedation. The Er:YAG laser was provided by Sciton (California) and was applied as a final step in two passes. For upper lids 70/60 microns plus coagulation 20. For lower lids $80 / 70$ plus coagulation 20 . The feathering area was 30 microns.

Her right eye had a silicone band from a previous surgery due to a retinal detachment performed 14 years earlier. The patient was evaluated by a retina specialist who found no contraindication to the aforementioned procedure.

There were no other ocular or overall physical dysfunctions.

The surgery and immediate post operative period evolved adequately.

Approximately one month after surgery, she began experiencing some discomfort in her right eye. Upon performing a slit lamp examination, an extrusion of the ends of the suture of the retinal band was observed through the conjunctiva (Figure 2). A new retinal examination was scheduled and the stitch was removed. After six months, there were no further complications (Figure 1).

The authors have been unable to find any references to link retinal bands and trans-conjunctival blepharoplasty [5].

\section{Discussion and Conclusion}

One possible explanation for the patient's complaint is that no matter how meticulous the joining of the borders of the incision are in this delicate conjunctival suture, this fragile membrane experiences a mild traction; therefore, if the ends of the suture on the silicone band are not hidden between its extremes, there is a strong possibility that
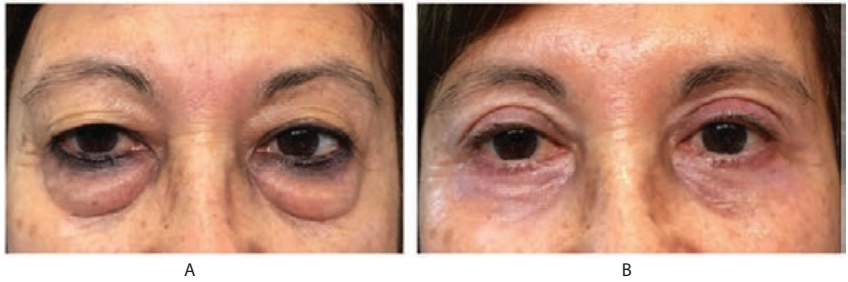

Figure 1: A-Preoperative. B-Postoperative at 6 months.

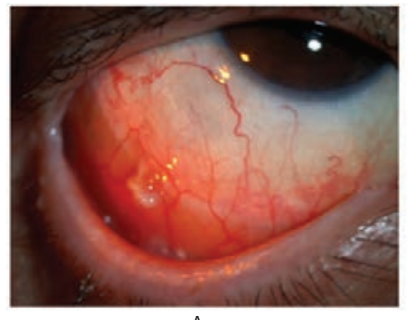

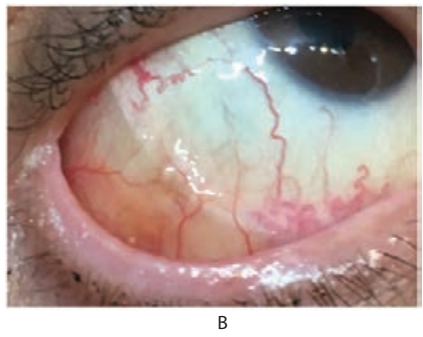

Figure 2: A-Extrusion of suture and inflammation of surrounding conjunctiva in the inferolateral quadrant of the globe. B-Five days after stich removal. 


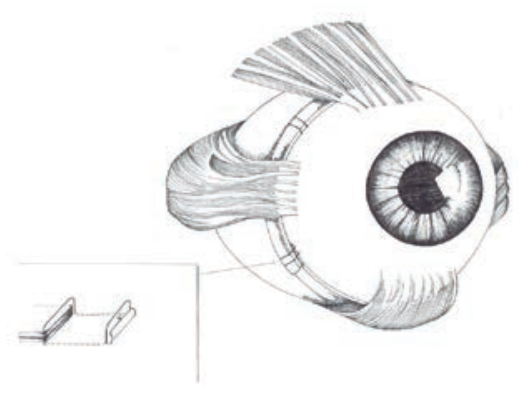

Figure 3: A suggested way to anchor the silicone band with the suture..

they will protrude (Figure 3). Another preventative tip is to locate the ends of the silicone band in the superolateral quadrant of the globe instead of the inferolateral one, avoiding further bulging in an area that could be displaced by this surgical technique or other repair procedures.
In conclusion, awareness and extra attention must be given to retinal silicone bands upon performing a trans-conjunctival blepharoplasty.

\section{References}

1. Murri M, Hamill EB, Hauck MJ, Marx DP (2017) An Update on Lower Lid Blepharoplasty. Semin Plast Surg 31: 46-50.

2. Chen JL, Liu CH, Yi CG (2017) Transconjunctival Orbital Septum Fat Release and Preservation for Orbitopalpebral Sulcus in Lower Eyelid Blepharoplasty. Aesthetic Plast Surg 41: 568-572.

3. Bourquet J (1924) Les herniesgraisseuses de l'orbite; Notre traitement chirurgical. Bull Acad Med Paris 92: 1270-1272.

4. Tessier P (1973) The conjunctival approach to the orbital floor and maxilla in congenital malformation and trauma. J Maxillofac Surg 1: 3-8.

5. James Oestreicher, Sonul Mehta (2012) Complications of Blepharoplasty: Prevention and Management. Plast Surg Int 252368. 